\title{
Policies for pre-eclampsia and eclampsia prevention and management in Bangladesh
}

Kanij Sultana

Population Council

Amy Dempsey

Population Council

Follow this and additional works at: https://knowledgecommons.popcouncil.org/departments_sbsr-rh

Part of the Demography, Population, and Ecology Commons, Family, Life Course, and Society Commons, International Public Health Commons, Maternal and Child Health Commons, and the Women's Health Commons How does access to this work benefit you? Let us know!

\section{Recommended Citation}

Sultana, Kanij and Amy Dempsey. 2017. "Policies for pre-eclampsia and eclampsia prevention and management in Bangladesh," Ending Eclampsia Brief. Washington, DC: Population Council. 


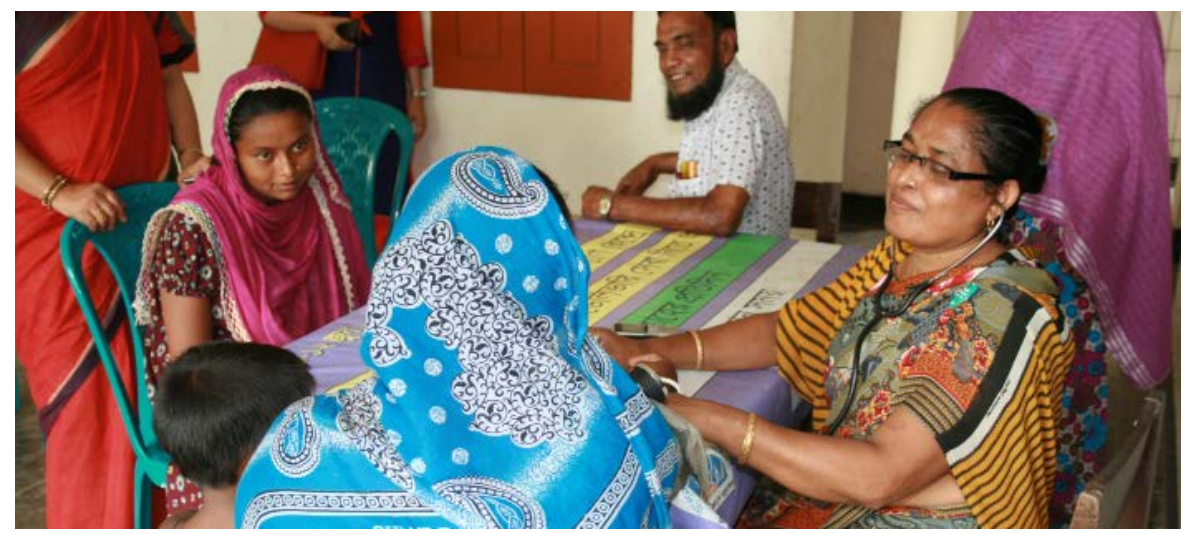

\section{POLICIES FOR PRE-ECLAMPSIA AND ECLAMPSIA PREVENTION AND MANAGEMENT}

Each day, more than 830 women and 7,200 babies die from pregnancy- or childbirth-related causes. These complications also lead to 7,000 stillbirths daily. Ninety nine percent of these deaths occur in developing countries. Despite global efforts to reduce preventable maternal and newborn mortality, Bangladesh still experiences between 5,000 and 6,000 maternal deaths each year. Of those deaths, 20 percent are from pre-eclampsia and eclampsia (PE/E), the second most common direct cause of maternal mortality in the country. These deaths are preventable.

In Bangladesh, best practices to prevent $\mathrm{PE} / \mathrm{E}$ using aspirin and calcium and manage through task sharing and using magnesium sulphate $\left(\mathrm{MgSO}_{4}\right)$ and antihypertensive drugs have not been optimally examined.

\section{RESEARCH}

To appreciate the enormity of the problem, the Population Council conducted a landscape analysis in 12 upazilas in four districts. The study was cross sectional, and data collection activities included in-depth interviews (IDIs) with policy makers, development partners, program managers, and Ob/Gyn professionals and primary facility providers. The study's objective was to identify existing national policies and guidelines for PE/E management and prevention, as well as to document gaps in antenatal care (ANC) specifically related to PE/E.

\section{Recommendations}

- Communicate national $\mathrm{PE} / \mathrm{E}$ policy and guidelines to all stakeholders, program managers, and service providers.

- Distribute national policies throughout the health system, including primary facilities.

- National policies include prevention and management of PE/E protocols at secondary and tertiary facilities.

- Train providers at primary and secondary facilities on prevention and management of PE/E.

- Collaborate with pharmaceutical companies to manufacture and package single IM loading dose of $\mathrm{MgSO}_{4}$.

- Introduce task sharing policy for the administration of aspirin and antihypertensive drugs by primary facility providers.
The Population Council conducts research and delivers solutions that improve lives around the world. Big ideas supported by evidence: It's our model for global change. popcouncil.org (c) 2017 The Population Council, Inc.
POPULATION COUNCIL

Ideas. Evidence. Impact. 


\section{FINDINGS}

\section{Government policies}

National policies for maternal health and standard operating procedures encompass prevention and management of complications like $\mathrm{PE} / \mathrm{E}$, but there is no specific policy that outlines detection, prevention, and treatment.

A developed, tested, and approved protocol for primary health care $(\mathrm{PHC})$ providers, ready for implementation in the field, has not yet been circulated, and program managers and service providers are unaware it exists.

"I don't know about the government policy. There might be one, but I cannot tell you about it, as I didn't get the policy in my hand. I don't know about where the policy is being implemented. There is no implementation policy in my district or upazilas. "

Policy Maker and Program Manager, MoHFW

\section{Task sharing}

Interviewees were aware of evidence about task sharing for detecting and managing PE/E using the loading dose of $\mathrm{MgSO}_{4}$ and referring women to secondary and tertiary facilities. Almost all policy level respondents believe that task sharing to lower cadre providers can have a positive impact on maternal health outcomes. They stressed the need for proper training and mentoring of lower level providers, however.

"We say that we made progress toward the MDG goals, but still most of the deliveries are taking place at home. If there is any problem, they first come to the grass roots health workers. If we can make the service providers more aware and train them at the community level, then they can identify

$P E / E$, administer the loading dose of $\mathrm{MgSO}_{4}$ and refer. Then it will definitely have a good effect and will reduce maternal mortality."

UNFPA Participant

\section{Essential drugs for PE/E}

Magnesium sulphate, calcium gluconate and antihypertensive drugs are essential for providing comprehensive treatment of PE/E. The Directorate General of Family Planning (DGFP) does not suppy these drugs to its facilities, rather, they expect pregnant women presenting with $\mathrm{PE} / \mathrm{E}$ to be referred to a higher level facility with the appropriate medicines. In the Directorate General of Health Services (DGHS), $\mathrm{MgSO}_{4}$ and calcium gluconate (the antidote to $\mathrm{MgSO}_{4}$ toxicity) are supplied irregularly by the
Central Medical Store of Drugs (CMSD) to District Reservation Stores (DRS). If these medicines are supplied to DRS, they are either stored there or sent to the district hospitals (DH) or upazila health complexes (UHC), depending upon the need.

The DGHS allocates 20 percent of its budget to the CMSD to locally procure medicines, including antihypertensive drugs, usually purchased quarterly through CMSD or by local purchase through a competitive bidding process. In exploring the reasons for irregular supply of these drugs, where the incidence of PE/E is lower, facilities appear to not use the drugs frequently and many drugs in expire on the shelves.

\section{Prevention measures}

Aspirin is not seen as a preventive drug for PE/E and there is no policy. Calicum is regularly supplied to pregnant women during ANC, although many providers are unaware of its use in preventing pre-eclampsia.

\section{Improving the referral system}

Interviewees were evenly divided about functionality of the current referral system. Half of the respondents believe it functions well, while others disagree. All belive it needs to be strengthened, however.

\section{"In the health system, the entry and exit points for a patient are not fixed. For the common cold, pa- tients are going to Dhaka Medical College Hospital, as well as to Community Clinics. Then how does the referral system work? Sending the patient with only a referral slip is not a true referral. It is not followed appropriately. We need to discuss the issue of the referral system at national level."}

\section{Deputy Director, DGFP}

Reducing deaths from $\mathrm{PE} / \mathrm{E}$ in Bangladesh is possible. Essential drugs and equipment must be available in facilities, and providers at all tiers of the health system must know detection, prevention, and treatment measures and be able to refer women for management.

\section{FOR MORE INFORMATION}

Kanij Sultana at Ksultana@popcouncil.org, info@endingeclampsia.org

For more information, visit www.endingeclampsia.org.

Citation: Warren, Charlotte, Sharif Hossain, Rahat Ara Nur, Kanij Sul tana, Karen Kirk, Amy Dempsey. 2015. "Landscape Report on Pre-eclampsia and Eclampsia in Bangladesh." Washington, DC: Population Council. 